\title{
Dinámicas de legitimidad en la instrumentación de la Marca Colectiva Chackay, en las reservas de la biósfera de Sian Ka'an y Banco Chinchorro, Quintana Roo, México
}

\author{
Dynamics of Legitimacy in the Instrumentation of the Chackay \\ Collective Brand in the Sian Ka'an and Banco Chinchorro \\ Biosphere Reserves, Quintana Roo, Mexico
}

Víctor Manuel Velázquez Durán ${ }^{1}$ y Rocío Rosales Ortega ${ }^{2}$

\section{Resumen}

Este artículo analiza las diversas formas de legitimidad (cognitiva, moral, pragmática) que se articularon en la organización de la Marca Colectiva Chackay, en la pesca de langosta espinosa que se desarrolla en las reservas de Sian Ka'an y Banco Chichorro, Quintana Roo. Con base en 36 entrevistas semiestructuradas a los miembros de las seis cooperativas pesqueras que operan en el área de estudio, fue posible analizar la legitimidad, representación y dificultades de inclusión de los pescadores locales, en el diseño e instrumentación de esta iniciativa de certificación ambiental. El trabajo muestra que el predominio de los intereses económicos sobre los argumentos conservacionistas de la asociación civil que impulsó la iniciativa, condicionó su relación con los actores que definen la gobernanza local (cooperativas de pescadores, ONG, instancias gubernamentales). Concluimos que los instrumentos de gestión ambiental deben prestar especial atención a la gran heterogeneidad de prácticas sociales y económicas de los actores que participan en una actividad productiva, en un contexto territorial específico.

Palabras claves: certificaciones ambientales voluntarias; legitimidad cognitiva; legitimidad moral; legitimidad pragmática; credibilidad;

\footnotetext{
${ }_{1}^{1}$ Candidato a doctor en Geografía por la Universidad Nacional Autónoma de México (UNAM), México. Líneas de interés: gobernanza económica-ambiental, cadenas sustentables de valor y ecología política. ORCID: https://orcid.org/0000-0002-3408-5853. Correo electrónico: victoraztyan@gmail.com

2 Autora de correspondencia. Doctorado en Geografía por la Universidad Nacional Autónoma de México (UNAM), México. Profesora-investigadora de la Universidad Autónoma Metropolitana-Unidad Iztapalapa, México. Líneas de interés: gobernanza económico-ambiental, cadenas sustentables de valor y desarrollo económico local. ORCID: https://orcid.org/0000-0003-3528-7956. Correo electrónico: rro@xanum.uam.mx
} 


\begin{abstract}
This article analyzes the various forms of legitimacy (cognitive, moral, pragmatic) articulated in the organization of the collective brand Chackay, focusing on the spiny lobster fishing in the reserves of Sian Ka'an and Banco Chinchorro, Quintana Roo. Based on 36 semi-structured interviews with the members of the six fishing cooperatives operating in the study area, it was possible to analyze the legitimacy, representation, and difficulties, including local fishermen in the design and implementation of this environmental certification. The work shows that the predominance of economic interests on the conservationist arguments of the civil association that promoted this initiative conditioned its relationship with the actors that define local governance (fishermen cooperatives, non-government, government organizations). We conclude that environmental management instruments should pay special attention to the high heterogeneity of social and economic practices of the actors that participate in productive activities, in a specific territorial context.
\end{abstract}

Keywords: cognitive legitimacy; credibility; moral legitimacy; pragmatic legitimacy; voluntary environmental certification.

\title{
Introducción
}

Esta investigación tiene como principal objetivo analizar las dinámicas de legitimidad que se generaron durante la organización de la Marca Colectiva Chackay, como una experiencia de certificación ambiental de la pesca de langosta espinosa en las reservas de la biósfera de Sian Ka'an (SK) y Banco Chinchorro (BCH), en el estado de Quintana Roo. En particular nos interesa comprender el proceso de construcción de la legitimidad de las certificaciones ambientales, por medio de las complejas negociaciones entre los actores e instancias gubernamentales que intervienen en su instrumentación, en distintas escalas territoriales. De esta manera, analizamos las diversas formas de legitimidad (cognitiva, moral, pragmática) que se interrelacionan en los procesos de certificación, las cuales se expresan en variadas trayectorias de reconversión sustentable de las cadenas de valor alimentarias a escala local.

La organización del artículo inicia con la explicación de la legitimidad de las certificaciones ambientales y sus diferentes expresiones en el territorio (cognitiva, moral, pragmática), prestando especial atención a las dificultades que enfrenta su instrumentación en el contexto de la actividad pesquera, en los países en vías de desarrollo. Más adelante exponemos la estrategia metodológica de la investigación, y reflexionamos sobre los problemas de legitimidad, representación e inclusión de los actores involucrados en el diseño e instrumentación de la Marca Colectiva Chackay. Posteriormente, 
estudiamos el proceso de construcción de la legitimidad de Ecosustentables ${ }^{3}$ y los arreglos institucionales que generó en la constitución de la marca, en función de la colaboración y las negociaciones con los actores que participan en la gobernanza de la pesca de langosta espinosa a escala local. En las conclusiones reflexionamos críticamente sobre las limitaciones de las certificaciones ambientales voluntarias que se diseñan con base en una legitimidad pragmática, con una escasa consideración del medio ambiente y los beneficios para las poblaciones locales.

\section{Legitimidad de las certificaciones ambientales voluntarias}

Las certificaciones ambientales voluntarias ${ }^{4}$ se definen como instrumentos privados de regulación que buscan modificar el comportamiento de los actores sociales, para promover prácticas de producción y/o pesca más amigables con el medio ambiente (Ponte et al., 2011). Se constituyen como innovaciones sociales que pueden dar lugar a regulaciones más efectivas para la reconversión sustentable de la producción alimentaria (Cadman, 2011).

Debido a que las certificaciones voluntarias carecen de los mecanismos formales de legitimidad del Estado, ${ }^{5}$ su credibilidad está condicionada por la valoración que realizan los actores locales sobre los discursos, acciones y comportamientos de los agentes privados externos (empresas, ONG) que diseñan e instrumentan las certificaciones. Dicha valoración se sustenta en las expectativas y/o demandas específicas de legitimidad de los actores en el territorio (Suchman, 1995; Cashore, 2002; Bostrom y Hallstrom, 2010; Glasbergen, 2013).

La construcción de la legitimidad es un proceso dinámico, multidireccional y cambiante, fruto de las negociaciones entre los diversos actores que participan en la instrumentación de las certificaciones. Así, los agentes externos desarrollan estrategias discursivas y acciones con el fin de participar en la gobernanza de los territorios, las cuales son aceptadas o

\footnotetext{
${ }^{3}$ Los pescadores entrevistados solicitaron que no se mencionaran sus nombres, así como el de la asociación que promovió la iniciativa, con el fin de evitar conflictos con otros actores que intervienen en la pesca de langosta espinosa.

${ }^{4}$ Las certificaciones ambientales voluntarias han adquirido un papel importante en la configuración de los mercados alimentarios en los últimos 20 años, debido a tres razones principalmente: 1) El interés del Estado por delegar responsabilidades en torno a los asuntos ambientales entre los diversos actores de la sociedad civil; 2) La incapacidad del Estado para atender adecuadamente las problemáticas ambientales asociadas con la producción de los alimentos (erosión de la tierra, deforestación, sobreexplotación de las pesquerías, entre otros); y 3) El papel hegemónico de las grandes corporaciones minoristas en la configuración de redes globales de producción y comercialización alimentarias (Ponte et al., 2011; Glasbergen, 2013; Mol, 2018).

${ }^{5}$ Entre los mecanismos que le otorgan legitimidad al Estado en los asuntos ambientales, se encuentran: 1) Los procesos de elección de los actores gubernamentales que podrán intervenir en la toma de decisiones; y 2) Las leyes establecidas en la constitución que se traducen en el poder regulatorio del Estado, para incidir en la construcción de las normas y reglas que definen las condiciones de uso, acceso y aprovechamiento de los recursos naturales (Cadman, 2011; Mol, 2018).
} 
rechazadas por los actores locales de acuerdo con sus intereses y necesidades (Bostrom y Hallstrom, 2010; Shouten, 2013; Miller y Bush, 2014).

De esta manera, la legitimidad de las certificaciones ambientales se define en buena medida por su capacidad de deliberación, la cual se reproduce a través de tres procesos: 1) la representación, que consiste en brindarles una posición equitativa a los diversos actores sociales en el proceso de diseño e instrumentación de la certificación; 2) el consenso, que permite mitigar los conflictos derivados de las diferentes visiones e intereses de los actores; y 3) efectos democráticos de las certificaciones, expresados en beneficios colectivos y equitativos en los territorios (Cheyns, 2011; Shouten, 2013). Estos tres procesos adquieren configuraciones específicas de acuerdo con las características socioculturales y políticas de cada territorio.

\section{Territorialidad de la legitimidad}

La categoría de ajuste institucional (institutional fit) permite comprender la instrumentación de las certificaciones ambientales como un proceso anidado (nestedness) de instituciones con diferentes niveles de jerarquía en la gestión de los recursos naturales (normas comunitarias, leyes del estado, arreglos transnacionales), el cual se expresa en distintas formas de legitimidad de los actores que buscan incidir en el cambio institucional de los territorios (Vandergeest et al., 2015; Van Koppen y Bush, 2018) .

Desde esta perspectiva, la instrumentación de las certificaciones ambientales se analiza como un proceso multiescalar, en el que los actores sociales interactúan de forma dinámica en la construcción de las instituciones en distintas escalas. A escala global y nacional se plantean regulaciones económico-ambientales genéricas que son aplicadas en diversos contextos territoriales, las cuales, en muchos casos, fracasan por su incapacidad para reconocer las particularidades de los territorios. Por lo tanto, los esquemas de certificación deben integrar a las instituciones construidas a escala local, con el fin de tener éxito en la reconversión sustentable de la producción alimentaria y la conservación de los ecosistemas (Thi Anh et al., 2011).

La escala meso-social posibilita el surgimiento de plataformas de coordinación-negociación multiescalar, que ayudan a mitigar los conflictos entre los diversos actores que intervienen en los procesos de certificación, propiciando regulaciones ambientales que articulan instituciones genéricas (globales-nacionales) y específicas (locales), para responder a la variedad de problemáticas socio-ambientales asociadas con la producción de alimentos en los territorios (Rasmussen et al., 2019; Oosterveer, 2018).

De esta manera, la legitimidad de las certificaciones se expresa en distintas formas de anclaje territorial: a) La legitimidad cognitiva se constituye a través de normas, reglas y prácticas fuertemente ancladas al 
territorio en el que se instrumentan las certificaciones; b) La legitimidad moral, por su parte, se sustenta en arreglos institucionales que se construyen en la escala meso-social, fruto de la negociación y/o coordinación entre actores en distintas escalas; y c) La legitimidad pragmática se asocia con instituciones de carácter genérico que son diseñadas por los agentes externos al territorio (Suchman, 1995; Fuchs y Glaab, 2011; Schouten, 2013).

A continuación, analizamos la configuración de estas tres dimensiones de la legitimidad (cognitiva, moral y pragmática), con base en la articulación de las siguientes categorías: a) redes sociales fuertes y débiles, b) proximidad geográfica, social y organizacional, c) tipos de certificaciones (descontextualizadas/participativas), y d) formas de organización de las cadenas de valor (convencionales/alternativas).

\section{Legitimidad cognitiva}

La legitimidad cognitiva se desarrolla por medio del entendimiento tácito de las normas y reglas, el cual es producto de la proximidad geográfica y sociocultural que comparten los actores en un espacio determinado (vinculada al concepto de comunidad). Dicha proximidad se expresa en lazos sociales fuertes (amistad, familiares, étnicos, morales, religiosos) que tienen una influencia importante en el comportamiento de los actores, dando lugar a una autoridad ampliamente aceptada en el territorio (Suchman, 1995; Hinrichs, 2000; 2016).

La legitimidad cognitiva está asociada a la instrumentación de certificaciones participativas-contextualizadas (ancladas territorialmente), caracterizadas por una interacción y comunicación más directa entre los productores y los consumidores, la inclusión de la diversidad de actores en los procesos de toma de decisiones, y una distribución más equitativa de los beneficios de la certificación (Loconto, 2015; Rosales, 2016).

Las certificaciones participativas pueden configurar cadenas alternativas de valor en las que existe una estrecha relación entre el contexto de la producción y el ecosistema que sustenta su desarrollo, y, por lo tanto, los productos certificados están anclados a las particularidades socioculturales y ambientales del territorio donde se sitúa la cadena (Rosales, 2016). Así, las relaciones cara a cara (proximidad geográfica) pueden dar lugar a arreglos de gobernanza (proximidad social y organizacional) que favorezcan la conservación de las prácticas y los recursos naturales relacionados con el desarrollo de sus actividades productivas (Hinrichs, 2000; 2015). 


\section{Legitimidad moral}

La legitimidad moral ${ }^{6}$ se reproduce a través de formas flexibles de autoridad, ya que los agentes externos (empresas, ONG, asociaciones civiles) tratan de construir redes sociales fuertes con los actores locales para justificar su autoridad en el territorio; pero, al mismo tiempo, mantienen vínculos débiles en distintas escalas, para ganar credibilidad en los diferentes contextos territoriales donde se instrumentan las certificaciones ambientales (Bostrom, 2006; Glasbergen, 2013; Schouten y Bitzer, 2015).

En este sentido, las redes débiles ${ }^{7}$ son esenciales para la coordinación multiescalar que permite la definición de criterios compartidos de sustentabilidad en las iniciativas de certificación ambiental, con el fin de ajustar las regulaciones ambientales genéricas a las prácticas socioproductivas de los actores locales, y atender de manera más efectiva los problemas derivados de la explotación desmedida de los recursos naturales en los territorios (Oosterveer, 2018).

Sin embargo, en la instrumentación de la legitimidad moral participan actores con diversas motivaciones, visiones e intereses en torno al uso y aprovechamiento de los recursos naturales, lo cual se expresa en dificultades y conflictos en la definición de los criterios de sustentabilidad de la certificación: a) Los actores conservacionistas/ambientalistas se preocupan principalmente por reducir los impactos ambientales de la actividad económica, tales como la pérdida de biodiversidad, la sobreexplotación de las pesquerías, la degradación y/o destrucción de los ecosistemas, entre otros; b) Los actores con una visión más balanceada entre los aspectos ambientales y socioeconómicos, reconocen la importancia de la preservación de los recursos naturales sin perder de vista el desarrollo económico de las comunidades locales; y c) Los actores con un fuerte énfasis en la mercantilización de la conservación, utilizan las certificaciones ambientales como una estrategia para incrementar la reputación de sus marcas en los mercados, sin considerar el medio ambiente y los beneficios para las poblaciones locales (Cheyns, 2011; Shouten, 2013; Mol, 2018).

\footnotetext{
${ }^{6}$ El concepto de legitimidad moral ha sido desarrollado en el estudio de las iniciativas multiactor y multiescalares de gestión ambiental, con el fin de comprender los conflictos que surgen como resultado de la coexistencia y/o contraposición de las justificaciones, discursos y acciones de los diversos actores que intervienen en los procesos de toma de decisiones, sobre el aprovechamiento de los recursos naturales en territorios específicos (Buscher y Dressler, 2007; Schouten y Bitzer, 2015; Mol, 2018; Oosterveer, 2018).

7 Las redes débiles se establecen más allá del entorno inmediato de los individuos. De acuerdo con Granovetter (1973), este tipo de redes fungen como un puente entre los niveles micro y macro de la vida social, permitiendo la articulación de los individuos con grupos sociales más amplios y heterogéneos. Así, las redes débiles son importantes para la transferencia de información y conocimientos complejos que no están al alcance de los individuos, permitiéndoles acceder a nuevas oportunidades y adaptarse a las condiciones cambiantes del exterior.
} 


\section{Legitimidad pragmática}

La legitimidad pragmática se relaciona con certificaciones ambientales basadas en reglas o normas estandarizadas o genéricas y por lo tanto cuenta con una limitada proximidad geográfica, social y organizacional entre los actores que participan en su instrumentación, generando un conocimiento descontextualizado territorialmente (Bostrom et al., 2015; Lockie et al., 2015).

La legitimidad pragmática se desarrolla por medio de redes sociales débiles entre los agentes que definen e instrumentan las reglas de la certificación y los actores que deben cumplirlas, propiciando arreglos de gobernanza que sustentan su credibilidad en cálculos sobre su efectividad y beneficios. Este tipo de legitimidad prioriza objetivos e intereses económicos y favorece comportamientos oportunistas en torno a la explotación de los recursos naturales (Suchman, 1995; Hinrichs, 2000; 2015).

Aunque diversos autores asocian la legitimidad pragmática con las cadenas convencionales de valor coordinadas por empresas minoristas transnacionales para imponer las certificaciones sustentables a los productores del sur global, ${ }^{8}$ nuestra investigación evidencia que las ONG o asociaciones civiles con discursos conservacionistas también pueden impulsar procesos de certificación en los que prevalece la racionalidad del mercado, los cuales tienen efectos limitados en la conservación de los recursos naturales y en el desarrollo socioeconómico de los territorios, propiciando conflictos sociales entre los actores locales.

Por lo tanto, es de gran relevancia comprender con mayor detalle las estrategias e intereses de las asociaciones civiles y/o ONG que impulsan los procesos de certificación ambiental, ya que sus discursos de legitimidad moral (conservacionista) pueden encubrir sus verdaderas intenciones, centradas en la maximización de sus ganancias (legitimidad pragmática). En el Cuadro 1 sintetizamos las características de los tres tipos de legitimidad que explicamos previamente y que guían el análisis en torno a la instrumentación de la Marca Colectiva Chackay.

\footnotetext{
${ }^{8}$ Ver trabajos de Neilson y Pritchard (2009); Vandergeest et al. (2015); Lockie et al., (2015) y Shouten y Bitzer (2015).
} 


\section{Cuadro 1. Características de las dinámicas de legitimidad}

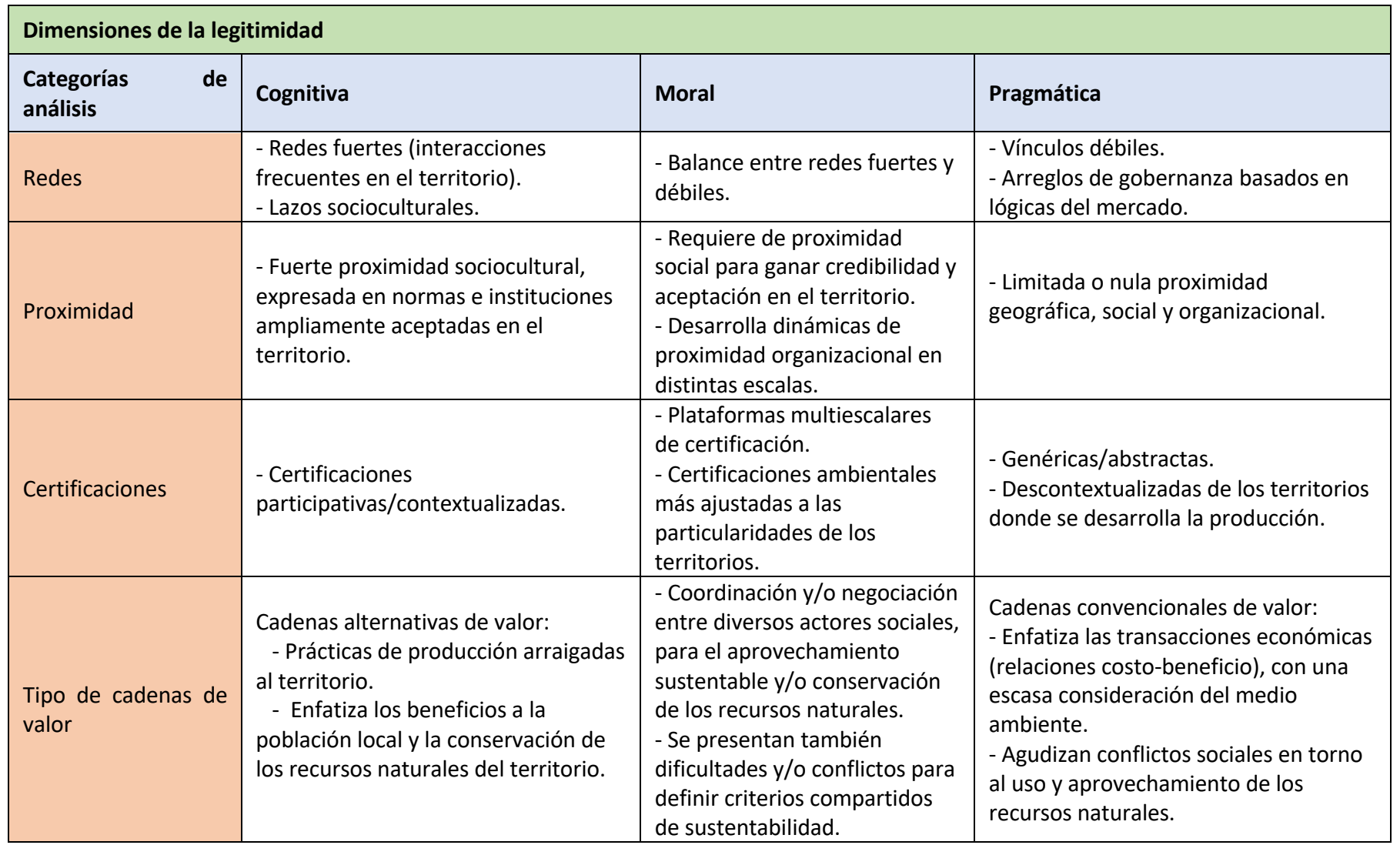

Fuente: elaboración propia (2019).

\section{Las certificaciones ambientales voluntarias en la pesca}

La certificación del MSC (Marine Stewardship Council) ${ }^{9}$ es el instrumento privado de regulación más importante para la pesca en la actualidad. Se estableció en 1997, y gradualmente ha ganado presencia a escala internacional, integrando a 386 pesquerías en su esquema de certificación ${ }^{10}$ (Bourillón, 2017; Bush y Oosterveer, 2019). No obstante, sólo el 7 \% de las pesquerías certificadas bajo el MSC se ubican en los países en vías de desarrollo, lo que pone en tela de juicio su capacidad para atender las

\footnotetext{
${ }^{9}$ Los orígenes de la certificación del MSC se remontan al año 1995, cuando la empresa Unilever se coordinó con la ONG internacional Fondo Mundial para la Naturaleza, para crear un esquema de certificación que promoviera la conservación en la actividad pesquera mediante incentivos del mercado: incremento de precios de los productos pesqueros y acceso a consumidores preocupados por el medio ambiente (Ponte, 2012).

${ }^{10}$ La evaluación del MSC se basa en tres aspectos generales de las pesquerías: 1) el nivel de explotación de los recursos pesqueros, 2) el impacto de la actividad sobre el ecosistema, y 3) examinar la correspondencia del sistema de gobernanza de la pesquería con las normas nacionales e internacionales que favorecen el aprovechamiento sustentable de los recursos pesqueros (Ponte, 2012; Pérez et al., 2015).
} 
problemáticas socioambientales relacionadas con la pesca en estos países (Bush y Oosterveer, 2019).

En México, la certificación del MSC se limita sólo a dos pesquerías con flotas industriales (la pesquería de la sardina del Pacífico del Golfo de California, y la pesquería de atún aleta amarilla y barrilete con caña y línea de Baja California), y a una pesquería artesanal-comunitaria (la langosta roja de Baja California) (www.msc.org; Bourillón, 2017).

En este sentido, la instrumentación de la certificación del MSC enfrenta las siguientes dificultades en México y América Latina: 1) las políticas de conservación aplicadas a la actividad pesquera son frágiles por no considerar el estado de las especies en el largo plazo; 2) los mecanismos de control y monitoreo de las prácticas de pesca son deficientes; 3) existe una limitada compatibilidad entre las regulaciones locales y nacionales/federales; 4) no se toma en consideración las limitaciones financieras y tecnológicas de los pescadores artesanales para responder a un esquema de certificación tan costoso; y 5) su concepción abstracta de la sustentabilidad les impide ajustarse a la gran variedad de contextos territoriales en donde se desarrolla la pesca a escala local (Pérez et al., 2012; Pérez et al., 2015; Gasalla y De Castro, 2016; Bush y Oosterveer, 2019).

La certificación del MSC reproduce una legitimidad pragmática que se sustenta en reglas abstractas del mercado para que los pescadores se ajusten a las demandas de las cadenas transnacionales de comercialización de los productos pesqueros (Ponte, 2012; Bush y Oosterveer, 2019). Como respuesta a esta tendencia de certificación, han surgido iniciativas que construyen formas de legitimidad más articuladas en los territorios donde se desarrolla la pesca. Por un lado, los procesos de cocreación buscan superar la visión de los pescadores como meros receptores de las certificaciones impuestas por los actores económicos externos, para concebirlos como agentes activos en el diseño e instrumentación de las certificaciones en sus territorios (Vellema y Van Wijk, 2015; Wentink et al., 2017). Por otra parte, existen diversas iniciativas de certificación promovidas por actores del Sur-global (southern standars), quienes intentan responder a la falta de legitimidad de los esquemas convencionales de certificación, para proponer regulaciones más efectivas en la conservación de los recursos pesqueros y la inserción de los pescadores locales en mercados más próximos (Ponte y Cheyns, 2013; Schouten y Bitzer, 2015; McClenachan et al., 2014; Guarin y Knorringa, 2013).

En este contexto, la asociación civil mexicana Ecosustentables promovió el desarrollo de la Marca Colectiva Chackay como una experiencia alternativa de certificación voluntaria en la pesca de langosta espinosa en las reservas de $\mathrm{SK}$ y $\mathrm{BCH}$. Las acciones que guiaron la propuesta se basaron en la activa participación de los pescadores locales, la conservación de la langosta y su hábitat, y el ingreso de los pescadores en redes de comercio más justas (Ley-Cooper y Quintanar, 2010). Sin embargo, la iniciativa tuvo 
alcances muy limitados en torno a la sustentabilidad y el desarrollo económico de las comunidades/localidades donde se sitúan las cooperativas pesqueras, y terminó desarrollando una legitimidad similar a las de los esquemas convencionales de certificación (legitimidad pragmática).

Por lo tanto, en los próximos apartados nos interesa responder a las interrogantes centrales de la investigación: 1) ¿Cuál fue el tipo de legitimidad que la asociación Ecosustentables construyó a través de la negociación con las cooperativas de pescadores, en las reservas de SK y BCH?, 2) ¿Cuáles fueron las dificultades que enfrentó la iniciativa para obtener credibilidad en la gobernanza local de la actividad?, y 3) ¿Cómo se desarrolló la participación de los pescadores locales en esta iniciativa?

\section{Metodología}

La presente investigación se sustenta en la realización de trabajo de campo entre los meses de marzo y abril del año 2018, tiempo durante el cual se llevaron a cabo 36 entrevistas semiestructuradas con pescadores que pertenecen a las seis cooperativas de pescadores en las reservas de SK y $\mathrm{BCH}$, en Quintana Roo (Cuadro 2).

Cuadro 2. Entrevistas realizadas durante el trabajo de campo

\begin{tabular}{|c|c|c|c|c|c|}
\hline Reserva & Cooperativa & $\begin{array}{l}\text { Número de } \\
\text { Socios }\end{array}$ & $\begin{array}{l}\text { Pescadores } \\
\text { entrevistados }\end{array}$ & Localidad & $\begin{array}{l}\text { Lugar de las } \\
\text { entrevistas }\end{array}$ \\
\hline \multirow{3}{*}{ Sian Ka'an } & Vigía chico & 70 & 9 & $\begin{array}{l}\text { Comunidad Javier } \\
\text { Rojo Gómez (Punta } \\
\text { Allen) }\end{array}$ & $\begin{array}{l}\text { - Casas particulares } \\
\text { - Parque comunitario } \\
\text { - Oficinas de la cooperativa }\end{array}$ \\
\hline & Cozumel & 48 & 5 & Centro de Cozumel & $\begin{array}{l}\text { - Oficinas de la cooperativa } \\
\text { - Casas particulares }\end{array}$ \\
\hline & $\begin{array}{l}\text { José María } \\
\text { Azcorra }\end{array}$ & 22 & 4 & Chetumal & - Oficina de la cooperativa \\
\hline \multirow{3}{*}{$\begin{array}{l}\text { Banco } \\
\text { Chinchorro }\end{array}$} & $\begin{array}{l}\text { Langosteros del } \\
\text { Caribe }\end{array}$ & $\begin{array}{c}-23 \text { socios } \\
-13 \text { aspirantes } \\
\end{array}$ & 6 & Chetumal y Mahahual & $\begin{array}{l}\text { - Oficinas de la cooperativa } \\
\text { - Casas particulares }\end{array}$ \\
\hline & $\begin{array}{l}\text { Andrés } \\
\text { Quintana Roo }\end{array}$ & $\begin{array}{l}-20 \text { socios } \\
-11 \text { aspirantes }\end{array}$ & 8 & Xcalak & $\begin{array}{l}\text { - Oficinas de la cooperativa } \\
\text { - Parque comunitario } \\
\text { - Playa }\end{array}$ \\
\hline & $\begin{array}{l}\text { Langosteros del } \\
\text { Banco } \\
\text { Chinchorro }\end{array}$ & $\begin{array}{l}-31 \text { socios } \\
-15 \text { aspirantes }\end{array}$ & 4 & Chetumal & - Oficina de la cooperativa \\
\hline
\end{tabular}

Fuente: elaboración propia (2019). 
Cabe mencionar que el trabajo de campo fue realizado durante la temporada de veda de la langosta espinosa, lo cual permitió desarrollar conversaciones informales y entrevistas a profundidad con los pescadores que disponían de más tiempo. El establecimiento del rapport ${ }^{11}$ fue muy importante para que los pescadores expresaran abiertamente sus impresiones sobre las acciones de los distintos actores que intervienen en la gobernanza de la pesca de langosta a escala local (instancias de gobierno, ONG/asociaciones civiles, científicos). Para generar confianza, las entrevistas se llevaron a cabo en el lugar indicado por los pescadores: oficinas de las cooperativas, viviendas de los pescadores, o en espacios públicos (parques, playas) de las localidades donde viven los entrevistados (Cuadro 2).

Los pescadores entrevistados fueron seleccionados a través de la técnica de la bola de nieve propositiva, ${ }^{12}$ de acuerdo con un conjunto de características que definimos antes de la visita de campo: 1) pescadores con una amplia experiencia en la pesca de langosta espinosa en la zona; 2) socios de las cooperativas que hayan formado parte de las mesas directivas durante el periodo de instrumentación de la Marca Colectiva Chackay; 3) pescadores que hayan participado directamente en la iniciativa, tanto en la empresa integradora como en el Consejo consultivo Chackay; y 4) pescadores que no tuvieron ninguna participación en el desarrollo de la marca.

Las entrevistas permitieron reconstruir la trayectoria de instrumentación de la marca Chackay, conocer las formas de participación y exclusión de los diversos pescadores locales, así como su percepción sobre los discursos y acciones de la asociación Ecosustentables, con el fin de comprender las relaciones y conflictos sociales que condicionaron la credibilidad y legitimidad de esta organización en la gobernanza local.

La investigación se sustenta principalmente en la perspectiva y opinión de los pescadores locales porque ellos fueron la población objetivo de esta iniciativa de certificación ambiental voluntaria, respaldada por dos instancias del gobierno federal: la Comisión Nacional para el Conocimiento y Uso de la Biodiversidad (CONABIO), y el Instituto Mexicano de la Propiedad Intelectual (IMPI). Por lo tanto, es relevante conocer con mayor detalle cómo impactó la iniciativa en la organización y desempeño de las agrupaciones locales de pescadores.

\footnotetext{
${ }^{11}$ El rapport es un elemento crucial en la investigación sobre la legitimidad de los actores en contextos determinados, ya que sólo después de haber logrado una genuina confianza con los informantes claves, podemos aproximarnos a temas sensibles durante las entrevistas, tales como el conflicto social, la reputación de los actores y grupos sociales, y las dinámicas del poder (Bernard, 2011; Schulz, 2017).

${ }^{12}$ La bola de nieve propositiva consiste en realizar un muestreo cualitativo de actores con base en los contactos que establecemos durante la investigación de campo. La muestra inicia con uno o más actores entrevistados, quienes posteriormente nos contactan con otros actores que pueden ajustarse al perfil de los entrevistados requerido para la investigación, hasta que llegamos a un punto de saturación con la información obtenida. El alcance de este muestreo está condicionado por la confianza y reputación que desarrolla el investigador con los grupos sociales entrevistados (Bernard, 2011).
} 
Para el procesamiento de la información obtenida durante el trabajo de campo, en primer lugar, transcribimos las entrevistas grabadas en audio, y posteriormente codificamos la información con base en las categorías de la legitimidad definidas en el marco teórico de la investigación (cognitiva, moral, pragmática), mediante el uso del software Atlas.ti.

\section{Instrumentación de la Marca Colectiva Chackay}

Entre los años 2005 y 2009, la asociación civil Ecosustentables diseñó e instrumentó la Marca Colectiva de la pesca de langosta espinosa en las reservas de Sian Ka'an (SK) y Banco Chinchorro (BCH), Quintana Roo, con el fin de promover una certificación voluntaria que contribuyera a la conservación de las poblaciones de langosta, al mismo tiempo que pudiera favorecer la inserción de los pescadores locales en mercados sustentables (Ley-Cooper y Quintanar, 2010). Esta iniciativa fue posible porque el representante de Ecosustentables pertenecía a la oficina de la Comisión Nacional de la Biodiversidad (CONABIO) ubicada en Chetumal, y al estar familiarizado con el Programa de Recursos Biológicos Colectivos (PRBC), ${ }^{13}$ decidió promover esta estrategia para fomentar el aprovechamiento sustentable de la langosta en las dos reservas. ${ }^{14}$

De este modo, personal de la oficina de la CONABIO ubicada en Chetumal, realizó las gestiones necesarias con las oficinas centrales de la Ciudad de México para financiar las primeras etapas del desarrollo de la Marca Colectiva, las cuales consistieron en la realización de talleres con los pescadores y la identificación de las tendencias de captura de la langosta. También desde esta oficina se realizaron las gestiones con el Instituto Mexicano de la Propiedad Intelectual (IMPI) para obtener el respaldo legal de la iniciativa, en el año 2009. Posteriormente, Ecosustentables gestionó las donaciones por parte del Fondo Mexicano para la Naturaleza (FMCN) y el Fondo para el Sistema Arrecifal Mesoamericano (SAM), las cuales complementaron los recursos con los que ya contaba la iniciativa (Ley-Cooper y Quintanar, 2010; Ley-Cooper, 2015).

La Marca Colectiva estableció la empresa integradora en el año 2008, en cuyas instalaciones se almacenaría la langosta capturada por las seis cooperativas de las dos reservas, para distribuir el producto sin intermediarios en los mercados finales. Así también, la empresa se

\footnotetext{
${ }^{13}$ En la instrumentación de los proyectos del PRBC, la CONABIO se coordina con asociaciones civiles y/o ONG para el diseño de estrategias que se ajusten a las necesidades y realidades de los productores locales. Además, son muy importantes las donaciones económicas realizadas por actores privados (empresarios, ONG nacionales e internacionales, etcétera) para que las iniciativas puedan sostenerse en el largo plazo (Larson, 2004).

${ }^{14}$ Entrevista con pescador que fungió como presidente de la empresa integradora.
} 
constituiría como la principal fuente de financiamiento para sostener la organización de la marca en el largo plazo (Ley-Cooper, 2010; 2015).

Asimismo, la iniciativa contaba con un Consejo consultivo que articularía a los distintos actores que participaban en la toma de decisiones sobre la pesca de langosta (cooperativas pesqueras, instancias gubernamentales, ONG, centros de investigación), para que los pescadores se ajustaran a las "reglas de uso de la Marca Colectiva", las cuales estaban enfocadas en mantener niveles de captura con un mínimo impacto en el ecosistema y hábitat de la langosta espinosa (Ley-Cooper, 2010; 2015).

Sin embargo, las dificultades en el diseño de la marca, la limitada confianza de los pescadores hacia Ecosustentables, y la competencia entre las diversas formas de legitimidad que tienen mayor aceptación en la gobernanza local, mermaron la credibilidad de la iniciativa, del promotor de la misma y sus alcances para incidir en la reconversión sustentable de la pesca de langosta. En la Figura 3 se muestran los actores, instancias y escalas de interacción que intervinieron en el desarrollo de la Marca Colectiva Chackay, que se mencionaron previamente.

\section{Figura 3. Instrumentación de la Marca Colectiva Chackay}

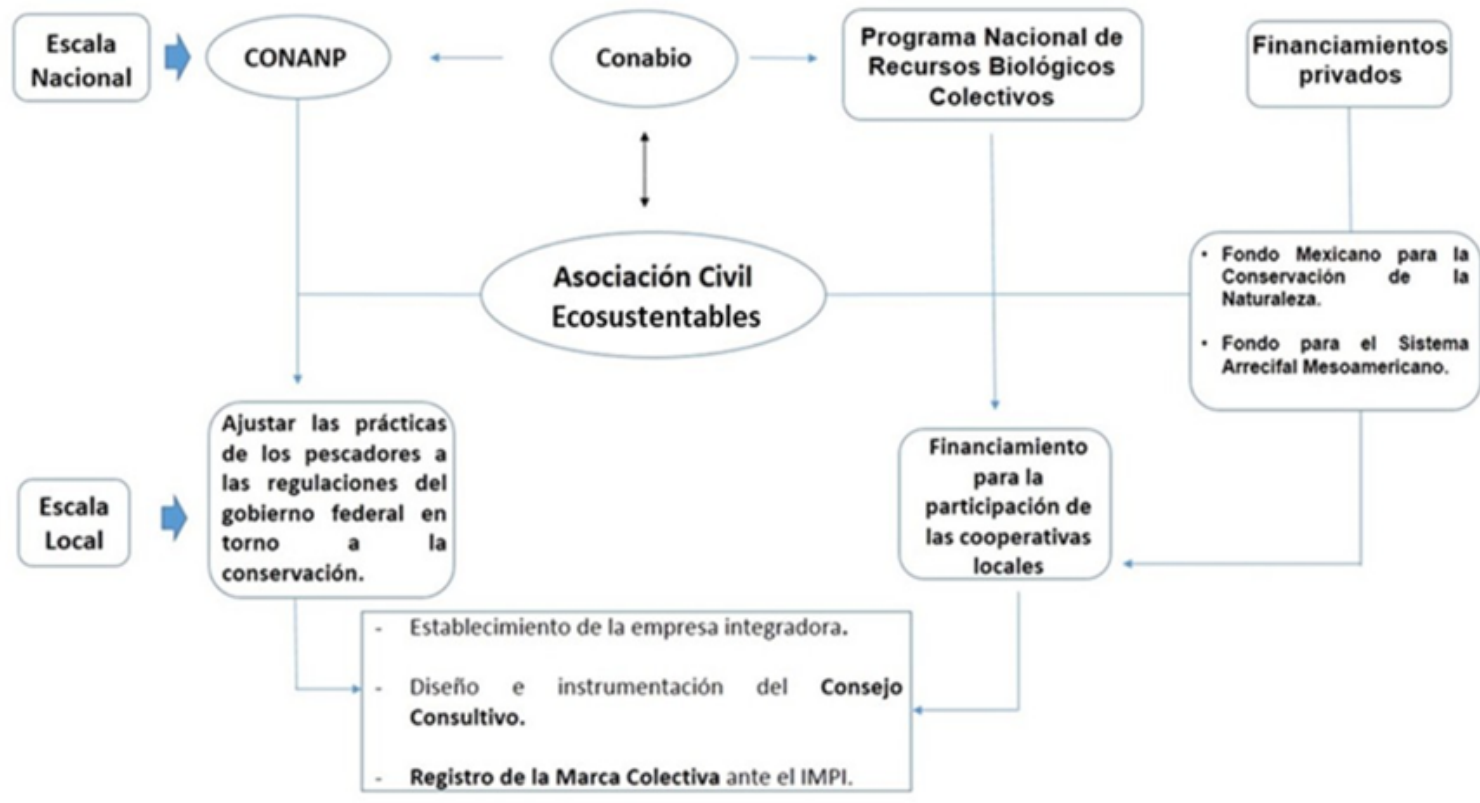

Fuente: elaboración propia, con base en Ley-Cooper y Quintanar (2010) 


\section{Problemas de representación y exclusión en instrumentación de la Marca Chackay}

Un problema importante en la construcción de la legitimidad de la Marca Colectiva Chackay consistió en que su diseño organizacional se basó en una concepción homogénea de los actores que formaron parte de la organización. $\mathrm{Al}$ considerar que las seis cooperativas de las reservas de Sian Ka'an (SK) y Banco Chinchorro (BCH) conformaban una pesquería sustentable integrada, no tomaron en cuenta las marcadas diferencias socioeconómicas y organizacionales entre ellas.

En este sentido, la justificación de la iniciativa se fundamentó principalmente en la organización de las dos cooperativas langosteras más exitosas del estado de Quintana Roo y de la reserva de Sian Ka'an ("Vigía chico" y "Cozumel"), las cuales tienen un amplio reconocimiento en la región por sus prácticas sustentables de captura, mismas que responden adecuadamente a las regulaciones ambientales de la Comisión Nacional de Áreas Naturales Protegidas (CONANP) y la Comisión Nacional de Acuacultura y Pesca (CONAPESCA). Además, la cohesión interna de estas agrupaciones favoreció un estricto monitoreo del cumplimiento de las normas por parte de sus afiliados, por lo que si un pescador utiliza alguna técnica de pesca que no esté permitida, ${ }^{15} \mathrm{o}$ si se le sorprende capturando langostas que no cumplen con el tamaño legal ${ }^{16}$ y en temporada de veda, ${ }^{17}$ son expulsados de las organizaciones.

Una de las innovaciones más importantes en la reserva de SK es el sistema de parcelas langosteras, ${ }^{18}$ el cual permite definir las áreas de captura de cada pescador, y en consecuencia disminuir la pesca ilegal que afecta la conservación del recurso langostero. Además, la instrumentación de esta innovación en toda la reserva ha ayudado a mitigar el conflicto entre las agrupaciones de pescadores por el acceso al recurso. Asimismo, en la actualidad las cooperativas langosteras que conforman la reserva de SK tienen una solidez financiera que se traduce en estabilidad social y política en su ambiente interno, así como en mejores condiciones de trabajo para los pescadores afiliados.

\footnotetext{
${ }^{15}$ La CONANP en su plan de manejo establece que sólo se permiten las siguientes técnicas de captura al interior de la reserva de Sian Ka'an: buceo a pulmón, jamo con canasto, refugios artificiales.

${ }^{16}$ La Ley de la Talla Mínima de la Langosta que regula la CONAPESCA, indica que sólo pueden ser capturadas las langostas con una cola de $13.5 \mathrm{~cm}$, mientras que las langostas juveniles y hembras ovígeras deben ser regresadas al mar sin ser lastimadas.

${ }^{17}$ La CONAPESCA establece que las capturas de la langosta espinosa sólo pueden realizarse entre los meses de julio y febrero, con el fin de evitar la sobreexplotación de la pesquería.

${ }^{18}$ El sistema de parcelas langosteras fue desarrollado por la cooperativa "Vigía chico" en la década de los setenta, con el fin de disminuir los conflictos entre los pescadores en torno al acceso al recurso langostero. Más recientemente, esta innovación fue difundida por la CONANP en la cooperativa "Cozumel", ubicada en la reserva de Sian Ka'an, con el fin de garantizar el desarrollo de una pesca sustentable al interior de la reserva en cuestión.
} 
En contraste, la pesca de langosta espinosa en la reserva de $\mathrm{BCH}$ presenta problemas importantes de organización. Las cooperativas "Andrés Quintana Roo" y "Langosteros del Banco Chinchorro" enfrentan dificultades financieras por la falta de transparencia en el manejo de los recursos económicos de las organizaciones. Lo anterior ha propiciado constantes conflictos en su interior, lo cual impide monitorear adecuadamente las prácticas de sus afiliados, propiciando el incumplimiento de las regulaciones de la CONANP y CONAPESCA.

En la reserva del $\mathrm{BCH}$, sólo la cooperativa "Langosteros del Caribe" ha logrado solventar sus problemas financieros y contar con una organización más estable. Esta solvencia económica se ha expresado en mejores ganancias para la organización $\mathrm{y}$, por consiguiente, ha permitido instrumentar gradualmente fondos de apoyo para mejorar las condiciones de trabajo de sus afiliados. La pesca en la reserva de $\mathrm{BCH}$ se caracteriza por el acceso abierto al recurso langostero, a diferencia del sistema de parcelas langosteras de la reserva de SK, lo que significa que no existen acuerdos formales entre las cooperativas para delimitar claramente las áreas de pesca de sus afiliados.

En este contexto, a pesar de que Ecosustentables desarrolló talleres con las seis cooperativas que conformaron la iniciativa de la Marca Colectiva Chackay, en el diseño de la marca quedaron principalmente plasmadas las características organizacionales de las cooperativas de SK, excluyendo las problemáticas y necesidades de las cooperativas del $\mathrm{BCH}$ :

En un principio nos buscaron y todo para entrarle a la Marca Chackay. Nos invitaron a sus talleres para comentarnos en qué consistiría la marca y cómo funcionaría. Pero al final creo que casi no nos tomaron en cuenta a los pescadores que estamos en el Banco Chinchorro, pues si tú ves toda la promoción de la marca se trata más que nada de la cooperativa que está en Punta Allen ("Vigía chico") y la de "Cozumel", y además realmente no vimos beneficios claros con la marca aun cuando estaba el nombre de nuestra cooperativa en los registros legales (pescador de una cooperativa ubicada en la reserva del $\mathrm{BCH})$.

Nosotros consideramos que la marca fue una iniciativa muy innovadora, pues buscaba atender el gran problema que siempre ha tenido el pescador de langosta: ser dependiente del intermediario. Te puedo decir que la cooperativa "Cozumel" fue la que más empujó esta iniciativa, y desde el principio tuvimos una buena relación con Ecosustentables. Creemos que la marca representa muy bien la visión e ideas de nuestra cooperativa para darle más valor a la langosta y buscar nuevos mercados, y por ello queremos seguir usando esta marca (pescador de la cooperativa "Cozumel", en la reserva de SK). 
En las dos citas observamos las visiones contrapuestas de los actores locales respecto a la iniciativa de la Marca Colectiva. Por un lado, en las cooperativas del $\mathrm{BCH}$ prevalece la idea de que sus intereses y necesidades fueron excluidos desde el comienzo de la certificación. Aunado a lo anterior, de los 18 pescadores que entrevistamos en esta reserva, nueve jamás fueron informados sobre este proyecto, y seis reconocieron que no hubo claridad en la información sobre su desarrollo y beneficios.

Mientras tanto, en la reserva de SK las opiniones sobre la Marca Colectiva Chackay y Ecosustentables son muy diversas. Todos los pescadores entrevistados en la cooperativa "Cozumel" tienen una opinión positiva sobre la Marca Colectiva y la asociación, pues consideran que sus intereses fueron bien representados en el diseño de la iniciativa, y perciben beneficios económicos tangibles en el uso de la marca. Sin embargo, la mayoría de los entrevistados en la cooperativa "Vigía chico" consideran que la marca no trajo ningún beneficio para la cooperativa, y que son las innovaciones sociales que ellos mismos han generado (sistema de parcelas, arreglos colectivos para la estabilidad financiera de la organización), las que han tenido efectos más importantes en la conservación de la langosta y en el bienestar de la comunidad.

A continuación, mostramos cómo se desarrollaron las relaciones y conflictos entre Ecosustentables y las diferentes agrupaciones de pescadores en SK y $\mathrm{BCH}$, para comprender las dificultades que enfrentó la Marca Colectiva y la asociación que la impulsó, para obtener credibilidad y legitimidad en la gobernanza de la pesca de langosta espinosa a escala local.

\section{Desarrollo de la empresa integradora de Quintana Roo}

La empresa integradora se estableció en el año 2008 con el fin de almacenar la captura y comercialización de la langosta de la Marca Colectiva Chackay. Los objetivos específicos de la empresa fueron: 1) pagar un precio justo por la langosta capturada en las seis cooperativas de las reservas de $\mathrm{SK}$ y $\mathrm{BCH}$; 2) erradicar la dependencia de los pescadores hacia los intermediarios, generando una demanda segura del producto; 3) monitorear que la langosta comercializada fuera capturada de forma sustentable, y 4) buscar mercados alternativos que pagaran un mayor precio por la captura de la langosta, lo cual permitiría incentivar y/o reforzar las prácticas sustentables de captura entre los pescadores locales. ${ }^{19}$

Las obligaciones que adquirieron las cooperativas, por formar parte de la empresa integradora fueron: 1) proporcionar el $30 \%$ de sus capturas anuales para sostener las operaciones de la organización, y 2) participar en las asambleas anuales de la empresa. Además, la mesa directiva quedaría

${ }^{19}$ Entrevista con pescador que fungió como presidente de la empresa integradora.

16 | Sociedad y ambiente, 23, 2020, ISSN: 2007-6576, pp. 1-30. doi: 10.31840/sya.vi23.2194 
conformada por los representantes de las seis cooperativas, para democratizar la toma de decisiones de la organización. ${ }^{20}$

En el proceso de establecimiento de la empresa integradora, Ecosustentables se coordinó con las seis cooperativas de SK y BCH para diseñar la etiqueta que llevarían los empaques de la langosta comercializada a través de la Marca Colectiva. La etiqueta brindaba información respecto al cumplimiento de la reglamentación por parte de los pescadores, sobre la talla mínima de captura y el uso de las artes de pesca, que no ponían en riesgo a la langosta y su hábitat. Sin embargo, la empresa integradora dejó de funcionar parcialmente porque no pudo obtener la cantidad de langosta necesaria para mantener sus operaciones, lo cual, a su vez, limitó el desarrollo de la Marca Colectiva ante la falta de incentivos para que los pescadores locales utilizaran la etiqueta Chackay.

Uno de los principales motivos del parcial fracaso de la empresa integradora fue que su reglamentación no contempló las diferencias en cuanto a las capacidades de captura entre las cooperativas de las reservas de SK y BCH. Las cooperativas de la reserva de SK no presentaron dificultades para entregar su producto porque contaban con la capacidad de captura necesaria (alrededor de 140 toneladas anuales) para responder a las demandas de la empresa integradora. Además, se beneficiaron de la ubicación de las instalaciones de la empresa en Cancún, a una distancia aproximada de $200 \mathrm{~km}$ de sus áreas de captura.

En cambio, los problemas financieros de las cooperativas del $\mathrm{BCH}$ impidieron que los pescadores contaran con el excedente de captura requerido por la empresa integradora. Así también, la distancia entre las cooperativas de esta reserva y las instalaciones de la empresa integradora representaba un costo más alto, debido a que la ciudad de Cancún se encuentra a una distancia aproximada de $400 \mathrm{~km}$ (Figura 4).

\footnotetext{
${ }^{20}$ Entrevista con pescador que fungió como presidente de la empresa integradora.
} 
Figura 4. Localización de las áreas de captura y la empresa integradora de la Marca Colectiva Chackay

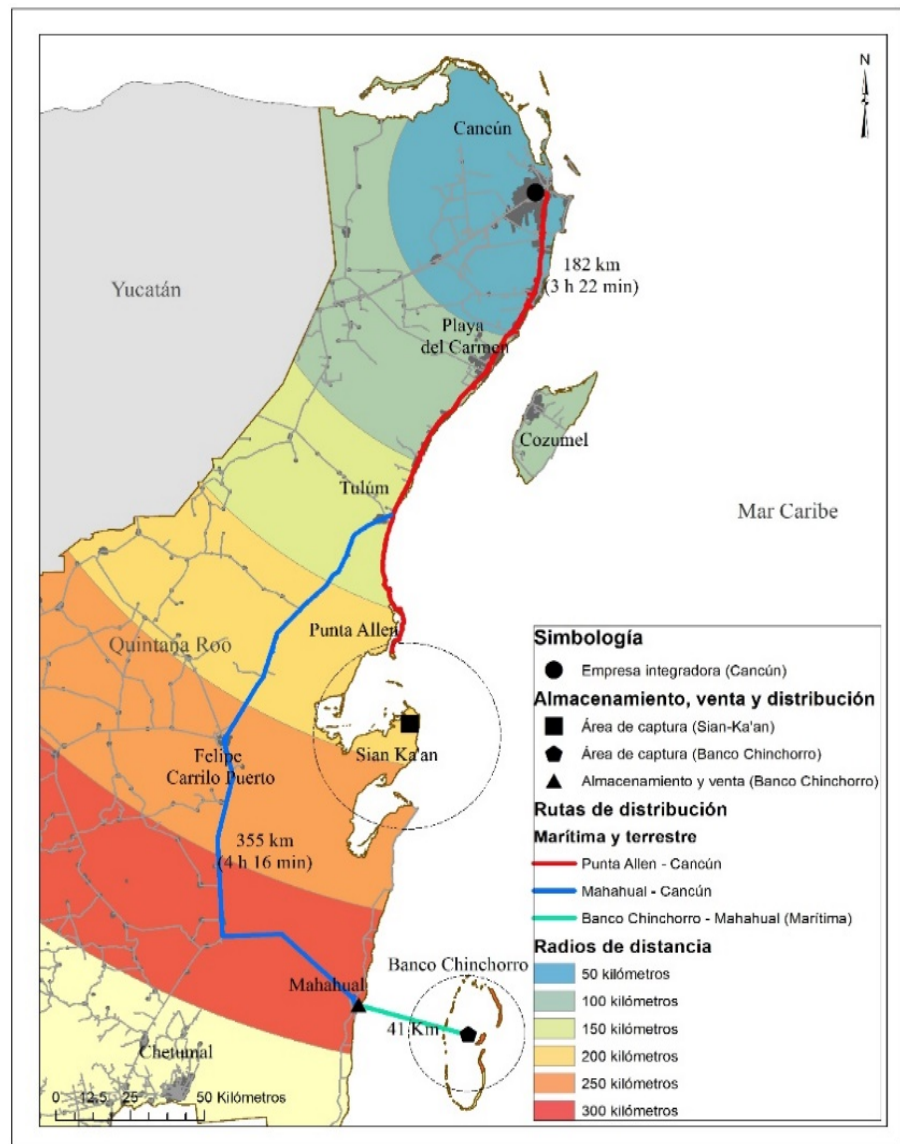

Fuente: elaboró Geog. Abel Vargas (2019).

Otro elemento que limitó los objetivos de la iniciativa de la Marca Chackay, fue que no encontró un mercado seguro para la langosta almacenada en la empresa integradora. Lo anterior se debió a que la mayor parte de la langosta capturada por los pescadores locales, es comercializada por intermediarios que se dirigen a los mercados asiáticos (China principalmente), los cuales no tienen interés en adquirir productos de origen sustentable y, por consiguiente, nunca aceptaron pagar un mayor precio por la etiqueta Chackay.

Como resultado del parcial fracaso de la empresa integradora, las cooperativas de la reserva del $\mathrm{BCH}$ continuaron vendiendo su langosta a través de intermediarios y sin ningún tipo de procesamiento, ya que su inestabilidad financiera les obliga a solicitar préstamos al comprador antes del comienzo de la temporada de captura, limitando sus posibilidades de obtener un mejor precio por la langosta. En contraste, y gracias a la solidez financiera de las cooperativas de SK, éstas han construido centros de acopio 
(congeladoras) en donde almacenan la langosta y, por lo tanto, pueden negociar un mejor precio con los compradores.

A pesar de que la iniciativa de la Marca Colectiva no prosperó, Ecosustentables decidió apoyar a la cooperativa "Cozumel" para mantener la etiqueta Chackay y vender su langosta a una empresa canadiense interesada en adquirir productos pesqueros sustentables. Los pescadores de esta agrupación lograron responder a las exigencias de la certificación ambiental porque previamente participaron en proyectos impulsados por el PNUD, ${ }^{21}$ para fortalecer la administración interna de su organización, mejorar las actividades de captura, procesamiento y venta de la langosta, así como incrementar el cumplimiento de las normas de la CONANP y CONAPESCA.

\section{Proceso de anidamiento institucional de la Marca Colectiva Chackay}

La aceptación y credibilidad de la Marca Colectiva Chackay se sustentó, por una parte, en el aprovechamiento de las coincidencias entre las regulaciones del gobierno federal en torno a la pesca de langosta, la legitimidad cognitiva de las cooperativas para el monitoreo de las prácticas de captura de los pescadores, y los vínculos que estableció la asociación Ecosustentables con científicos de diferentes centros de investigación, para generar los datos e información sobre la langosta y su hábitat.

\section{Complementariedad y competencia entre las dinámicas de legitimidad}

La iniciativa de la Marca Colectiva Chackay integró las regulaciones que instrumenta CONAPESCA de manera vertical (de arriba hacia abajo), las cuales no pueden ser negociadas por los actores locales, tales como las restricciones de veda que se enmarcan en la Ley General de Pesca, y la reglamentación de la talla mínima de las langostas que se respalda en la Norma Oficial Mexicana del aprovechamiento de la langosta. Así también, articuló las restricciones ambientales impuestas por la CONANP mediante los planes de manejo de las reservas de $\mathrm{SK}$ y $\mathrm{BCH}$.

Durante el proceso de instrumentación de la Marca Colectiva, Ecosustentables estableció lazos con las seis cooperativas que desarrollan la pesca de langosta en las reservas de $\mathrm{SK}$ y $\mathrm{BCH}$, con el fin de aprovechar la legitimidad cognitiva de sus representantes y ganar aceptación entre los diversos pescadores locales. Cabe resaltar que los representantes de las cooperativas aprovechan la proximidad geográfica y sociocultural con los pescadores afiliados, para construir una legitimidad cognitiva que les

${ }^{21}$ Programa de las Naciones Unidas para el Desarrollo. 
permite imponer reglas y sanciones estrictas que fomentan prácticas de captura moderadas, para preservar la actividad económica de la cual dependen sus comunidades. Así, las cooperativas se constituyen en los espacios de representación más importantes para los pescadores, por la confianza desarrollada a través de lazos sociales fuertes en el territorio (familiares, amistad, compadrazgo).

Un elemento importante en el proceso de establecimiento de la Marca Colectiva fue el monitoreo de las prácticas de captura de la langosta espinosa. Por lo tanto, Ecosustentables se coordinó con investigadores del Centro Regional de Investigación Pesqueras (INAPESCA), del Colegio de la Frontera Sur (ECOSUR) y del Instituto de Ciencias del Mar y Limnología de la UNAM en Puerto Morelos, con el fin de generar y sistematizar datos sobre las langostas capturadas en las dos reservas. Así, se creó un modelo de análisis permanente de las capturas, para que la Marca Colectiva obtuviera credibilidad ante los consumidores, garantizando que la langosta comercializada con la etiqueta Chackay era capturada de forma sustentable, con mínimas afectaciones sobre el hábitat y ecosistema de la especie.

La credibilidad de los científicos y/o investigadores se sustenta en dos elementos principalmente: 1) el conocimiento ambiental experto ${ }^{22}$ que han desarrollado sobre las problemáticas que afectan a las poblaciones de langosta espinosa en la zona (enfermedades, contaminación de hábitats y ecosistemas, contingencias climáticas por huracanes y/o frentes fríos), les permite contribuir a la instrumentación de estrategias para la conservación de la actividad y obtener reconocimiento por parte de las agrupaciones de pescadores; y 2) los científicos construyen su legitimidad a través de la creación de lazos sociales fuertes con los pescadores, los cuales posibilitan el intercambio continuo de información, para la generación de un conocimiento más ajustado a la realidad de la pesca de langosta en las dos reservas.

Sin embargo, la legitimidad de la Marca Colectiva se debilitó porque el parcial fracaso de la empresa integradora impidió que los pescadores locales obtuvieran los beneficios económicos esperados. Además, Ecosustentables optó por establecer lazos fuertes con una sola cooperativa ("Cozumel”), pues resultó más práctico continuar el desarrollo de la iniciativa con los pescadores que tenían menos problemas de organización. Así, la asociación civil promovió que la Marca Colectiva fuera reconocida como una experiencia exitosa de certificación ambiental, al mismo tiempo que excluyó a las cinco cooperativas consideradas en el proyecto original, de los beneficios esperados.

\footnotetext{
${ }^{22}$ Lidskog y Sundqvist (2018) señalan que la construcción de un conocimiento ambiental experto basado en la articulación de conocimientos abstractos (de la ciencia) y específicos (del mundo cotidiano de los actores sociales), puede ayudar a los científicos a obtener reconocimiento, credibilidad y legitimidad para opinar e intervenir en la atención a las problemáticas ambientales en determinados contextos territoriales.
} 
La falta de correspondencia entre su discurso de inclusión social y sustentabilidad y la instrumentación de sus acciones en la práctica, terminó por dañar la credibilidad de Ecosustentables en el contexto local, debido a que no desarrolló estrategias para apoyar a las cooperativas con problemas económicos y de organización en la reserva del $\mathrm{BCH}$, al mismo tiempo que sus esfuerzos orientados a la conservación, han sido limitados. En palabras del presidente de una cooperativa de pescadores de la reserva del $\mathrm{BCH}$ :

\begin{abstract}
Ecosustentables ha quedado mal con el pescador porque los beneficios que nos dijeron al inicio de la Marca Colectiva, nunca los vimos. Creo que los beneficios más fuertes se los quedó la "Cozumel”, ellos sí supieron aprovechar esto de la marca. Entonces cómo vamos a creerles ahora que vienen y quieren proponer algún proyecto de conservación y apoyo para el pescador. Realmente ya no sabemos si Ecosustentables es una ONG o una consultora, pues creemos que a veces sólo están buscando ganar dinero a costa del pescador.
\end{abstract}

\title{
Competencia en torno a la construcción de la legitimidad moral
}

En el proceso de instrumentación de la Marca Colectiva Chackay, la credibilidad de Ecosustentables tuvo que competir con la legitimidad moral de la asociación civil Comunidad y Biodiversidad (COBI), la cual ha incrementado notablemente su participación en la gobernanza de la pesca de langosta espinosa en las reservas de SK y $\mathrm{BCH}$ en los últimos años, debido a que ha impulsado iniciativas para contribuir a los esfuerzos de la conservación del recurso langostero.

Es importante mencionar que las políticas públicas para el desarrollo de la pesca de langosta espinosa en el estado de Quintana Roo, han sido diseñadas e instrumentadas con una participación limitada de los pescadores locales. Si bien el gobierno federal ha fomentado algunas plataformas de diálogo con los pescadores (Consejos estatales de pesca, Comités consultivos de pesca, Comités sistema-producto), estas iniciativas no han tenido los resultados esperados por la falta de coordinación entre las autoridades federales y los actores locales, impidiendo la construcción de políticas en la escala meso-social que se ajusten mejor a las diversas realidades de la pesca de langosta en las reservas de SK y BCH (Moreno et al., 2016).

En este contexto, tanto Ecosustentables como COBI instrumentaron plataformas de diálogo y colaboración en la escala meso-social, con el fin de articular a los diversos actores que intervienen en la gobernanza de la pesca de langosta espinosa en distintas escalas, y así responder de forma más efectiva a las problemáticas y necesidades específicas de los pescadores locales. Sin embargo, las dos asociaciones han tenido trayectorias muy 
distintas en la construcción de su credibilidad y legitimidad en la gobernanza local.

COBI ganó mucha credibilidad entre los pescadores locales, al instrumentar el proyecto de la delimitación de las zonas de refugio para mantener estables las poblaciones de langosta en las reservas de $\mathrm{SK}$ y $\mathrm{BCH}$. La colaboración entre COBI y las seis cooperativas pesqueras de las reservas derivó en la constitución de la plataforma FIP (Fishery Improvement Project), la cual ha permitido un mayor diálogo e interacción entre los actores que componen la gobernanza de la pesca de langosta espinosa. Lo anterior afianzó la aceptación y reconocimiento de COBI en el contexto local:

Sin duda COBI es una organización que tiene más claridad en sus objetivos. Con el tiempo hemos confiado más en ellos, y sus puntos de vista y sus conocimientos son importantes para que conservemos la langosta. El hecho de que nos permitan a todos los pescadores dar nuestra opinión, sin importar si eres de $\mathrm{SK}$ o $\mathrm{BCH}$, nos hace sentir que nuestras opiniones son igual de válidas, y entonces así uno se motiva a colaborar con esta organización (presidente de cooperativa ubicada en $\mathrm{BCH}$ ).

En definitiva, las dinámicas de legitimidad que coexisten en los territorios donde se desarrolla la pesca de langosta espinosa en $\mathrm{SK}$ y $\mathrm{BCH}$, se expresan en una gran variedad de políticas e iniciativas que se complementan o compiten en la definición de la sustentabilidad a escala local. En primer lugar, las regulaciones descontextualizadas que propone Ecosustentables (legitimidad pragmática), ofrecen escasas oportunidades para fomentar la organización de la cadena de valor de la langosta, por lo que los pescadores se mantienen en redes de comercio controladas por intermediarios que tienen un nulo interés en la sustentabilidad de los productos y la conservación de los recursos naturales. En la escala meso-social (legitimidad moral) puede existir un mayor diálogo entre los pescadores locales, los científicos y otras asociaciones civiles, para construir esquemas de certificación ambiental que valoricen las prácticas e innovaciones sociales desarrolladas por las cooperativas locales (legitimidad cognitiva), e impulsar su inserción en mercados más próximos y/o redes de comercio más justo (Cuadro 3). 


\section{Cuadro 3. Tipos de legitimidad y su interacción, en la instrumentación de la Marca Colectiva Chackay}

\begin{tabular}{|c|c|c|c|}
\hline Organizaciones & Ecosustentables & COBI & Cooperativas locales \\
\hline Tipo de legitimidad & Pragmática & Moral & Cognitiva \\
\hline Redes & $\begin{array}{l}\text {-Arreglos basados en la lógica del } \\
\text { mercado, con base en vínculos } \\
\text { débiles. }\end{array}$ & $\begin{array}{l}\text {-Vínculos fuertes en la } \\
\text { construcción de reglas de } \\
\text { organización de la actividad. }\end{array}$ & $\begin{array}{l}\text {-Redes fuertes por la continua interacción en la } \\
\text { organización de la actividad pesquera. } \\
\text {-Vínculos socioculturales por la convivencia en } \\
\text { la localidad, por las relaciones de parentesco y } \\
\text { de amistad. }\end{array}$ \\
\hline Tipos de proximidad & $\begin{array}{l}\text { - Limitada o nula proximidad } \\
\text { físico-geográfica. } \\
\text {-Limitada proximidad social en la } \\
\text { medida que no se involucró en } \\
\text { los problemas sociales de las } \\
\text { cooperativas. } \\
\text {-Limitada proximidad } \\
\text { organizacional, porque no } \\
\text { identificó las deficiencias ni } \\
\text { propuso soluciones a las } \\
\text { necesidades de las cooperativas. }\end{array}$ & $\begin{array}{l}\text { - Proximidad social y } \\
\text { organizacional generadas en el } \\
\text { proceso de instrumentación de } \\
\text { los proyectos de conservación. }\end{array}$ & $\begin{array}{l}\text { - Proximidad geográfica entre las cooperativas } \\
\text { ubicadas en una misma reserva. } \\
\text {-Proximidad sociocultural, por compartir el } \\
\text { conocimiento de las características y } \\
\text { problemas de la actividad pesquera. Así } \\
\text { también, por la aceptación de su autoridad en } \\
\text { las comunidades. } \\
\text {-Proximidad sociocultural por compartir } \\
\text { prácticas de convivencia social en sus } \\
\text { localidades. } \\
\text {-Proximidad organizacional entre las } \\
\text { cooperativas de SK por la organización de sus } \\
\text { cooperativas y la realización del trabajo. } \\
\text {-En cambio, las cooperativas de BCH, tienen } \\
\text { mayores dificultades de organización del } \\
\text { trabajo de la pesca y de sus cooperativas. }\end{array}$ \\
\hline $\begin{array}{c}\text { Tipos de } \\
\text { certificaciones }\end{array}$ & $\begin{array}{l}\text {-Genérica/abstracta } \\
\text { - Descontextualizada del } \\
\text { territorio en donde se } \\
\text { instrumenta. }\end{array}$ & $\begin{array}{l}\text { - La plataforma FIP genera la } \\
\text { organización de certificaciones } \\
\text { participativas. } \\
\text {-La organización asume que es } \\
\text { necesario ayudar a las } \\
\text { cooperativas a resolver sus } \\
\text { problemas internos. }\end{array}$ & $\begin{array}{l}\text { - Innovaciones sociales desde abajo. } \\
\text { - Requieren certificaciones ancladas } \\
\text { territorialmente. }\end{array}$ \\
\hline $\begin{array}{c}\text { Tipos de cadenas de } \\
\text { valor }\end{array}$ & $\begin{array}{l}\text { - Refuerza cadenas } \\
\text { convencionales de valor, basadas } \\
\text { en el predominio de las } \\
\text { transacciones económicas, sobre } \\
\text { los beneficios sociales de los } \\
\text { actores participantes. } \\
\text {-Agudiza conflictos entre los } \\
\text { actores que aprovechan un } \\
\text { recurso. }\end{array}$ & $\begin{array}{l}\text { - Fomenta la inserción de los } \\
\text { pescadores en cadenas } \\
\text { alternativas de valor. }\end{array}$ & $\begin{array}{l}\text { - Se interesan por mercados próximos. } \\
\text { - Se interesa por valorar y conservar las } \\
\text { prácticas locales de pesca. }\end{array}$ \\
\hline
\end{tabular}

Fuente: elaboración propia. 


\section{Conclusiones}

La instrumentación de las certificaciones ambientales voluntarias implica la interrelación dinámica entre la legitimidad de los actores y los arreglos institucionales que se construyen en los territorios. Así, los intereses, motivaciones y acciones de los actores que impulsan las certificaciones, se plasman en el conjunto de reglas y normas que buscan estimular prácticas sustentables de organización de la actividad económica. Sin embargo, los grupos sociales que conforman la población objetivo, tienen la capacidad de cuestionar la legitimidad y autoridad de las organizaciones que instrumentan mecanismos de certificación, si no resuelven de manera efectiva los problemas socioeconómicos y ambientales que los aquejan.

En este sentido, la instrumentación de la Marca Colectiva Chackay es un ejemplo de la construcción de la legitimidad de las certificaciones ambientales voluntarias. En un primer momento, Ecosustentables aprovechó la legitimidad del Estado, a través del Programa de Recursos Biológicos Colectivos de la CONABIO, para negociar la aceptación de la marca con las cooperativas que conforman la pesca de langosta en las reservas de Sian Ka'an y Banco Chinchorro. Posteriormente, la asociación intentó constituir su legitimidad moral por medio de un discurso ambientalconservacionista, y con la planeación del Consejo consultivo buscaba tejer redes con actores e instancias en distintas escalas. Sin embargo, la percepción de los pescadores hacia Ecosustentables fue cambiando gradualmente, porque la Marca Colectiva no respondió a las expectativas que se plantearon al comienzo de la iniciativa. Por lo tanto, la asociación no logró construir lazos sociales fuertes ni la confianza necesaria con los actores locales, para consolidar el Consejo consultivo y ganar aceptación en la gobernanza de la pesca de langosta.

Otro aspecto que limitó el desarrollo de la Marca Colectiva fue la falta de congruencia del discurso de legitimidad de Ecosustentables (predominio de los intereses económicos sobre el discurso conservacionista), ante la presencia de la asociación civil COBI, la cual está ganando una mayor aceptación y reconocimiento entre las cooperativas locales. Esta organización constituyó una plataforma de coordinación a escala meso-social, que ha posibilitado el diálogo y la colaboración entre actores en distintas escalas, para instrumentar una estrategia más efectiva e incluyente de conservación de la langosta y su hábitat (zonas de refugio).

Asimismo, la credibilidad y legitimidad de Ecosustentables se vio condicionada por su incapacidad de representar equitativamente los intereses y visiones de las seis cooperativas de $\mathrm{SK}$ y $\mathrm{BCH}$, a lo largo del proceso de instrumentación de la marca Chackay. Además, al no considerar adecuadamente las problemáticas y necesidades que presentan los pescadores del $\mathrm{BCH}$, los beneficios de la iniciativa fueron desiguales. 
A pesar de que la Marca Colectiva Chackay fue impulsada por una asociación civil mexicana, ésta no presenta las características de las certificaciones ambientales que están organizándose desde el sur-global (southern standards), las cuales sustentan su legitimidad en una mayor inclusión de los diversos actores de las cadenas de valor, para promover la inserción de los pescadores locales en redes de comercio más justas y amigables con el medio ambiente (Ponte y Cheyns, 2013; Schouten y Bitzer, 2015; Guarin y Knorringa, 2013; McClenachan et al., 2014). Por el contrario, la iniciativa reprodujo una legitimidad pragmática similar a la de las certificaciones pesqueras convencionales (Bush y Oosterveer, 2019), la cual se expresó en una limitada credibilidad en el contexto local, dejando a la mayoría de los pescadores locales bajo la subordinación de las cadenas transnacionales de comercialización, dirigidas principalmente al mercado chino que no se interesa por generar incentivos para la transformación sustentable de los alimentos pesqueros.

En definitiva, para instrumentar certificaciones voluntarias sustentables a escala local y se coordinen con las cadenas de valor alimentarias a escala global, se requiere desarrollar una mayor proximidad con las expectativas y/o demandas de los diversos actores involucrados. Por lo tanto, es crucial la construcción de una legitimidad moral (balance entre redes débiles y fuertes, proximidad organizacional en distintas escalas) y cognitiva (proximidad geográfica y sociocultural), las cuales, si bien requieren de mayor tiempo y esfuerzo en la organización de los actores locales, favorecen la instrumentación de certificaciones más incluyentes y con mayor efectividad en la atención de las problemáticas socioambientales de los territorios.

\section{Agradecimientos}

Se agradece a los pescadores de langosta de las reservas de Sian Ka'an y Banco Chinchorro, por abrirnos las puertas de sus cooperativas y proporcionarnos la información necesaria para la presente investigación.

\section{Referencias}

Bernard, Russell (2011). Research Methods in Anthropology. Qualitative and Quantitative Approaches. Reino Unido: AltaMira Press, 681 pp.

Bostrom, Magnus (2006). "Establishing Credibility: Practising StandardSetting Ideals in a Swedish Seafood-Labelling Case". Journal of Environmental Policy and Planning, 8 (2), pp. 135-158. 
Bostrom, Magnus y Hallstrom, Tamm (2010). "Global Multi-Stakeholder Standard Setters: How Fragile are they?” Journal of Global Ethics, 9(1), pp. 93-110.

Bostrom, Magnus; Jonsson, Anna; Lockie, Stewart; Mol, Arthur, y Oosterveer, Peter (2015). "Sustainable and Responsible Supply Chain Governance: Challenges and Opportunities". Journal of Cleaner Production, 107, pp. 1-7.

Bourillón, Luis (2017). "Certificación de pesquerías". Foro Económico de Pesca y Acuacultura. Ciudad de México, 29 de noviembre de 2017. Recuperado de https://foroeconomico.conapesca.gob.mx/historial/paginas/historial/2017/as sets/img/ponentes/LUIS_BOURILLON_MORENO_CERTIFICACION_D E PESQUERIAS.pdf

Buscher, Bram y Dressler, Wolfram (2007). "Linking Neoprotectionism and Environmental Governance: On the Rapidly Increasing Tensions Between Actors in the Environment-Development Nexus". Conservation and Society, 4(5), pp. 586-611.

Bush, Simon y Oosterveer, Peter (2019). Governing Sustainable Seafood. Nueva York: Routledge, 208 pp.

Cadman, Timothy (2011). Quality and Legitimacy of Global Governance: Case Lessons from Forestry. Nueva York: Palgrave Macmillan, 273 pp.

Cashore, Benjamin (2002). "Legitimacy and the Privatization of Environmental Governance: How Non-State Market-Driven (NSMD) Governance Systems Gain Rule-Making Authority". Governance: An International Journal of Policy, Administration, and Institutions, 15, pp. 503529.

Cheyns, Emmanuelle (2011). "Multi-stakeholder Initiatives for Sustainable Agriculture: Limits of the 'Inclusiveness' Paradigm?". En Stefano Ponte, Peter Gibbon y Jakob Vandergeest (eds.), Governing through Standards: Origins, Drivers and Limitations. Reino Unido: Palgrave, pp. 210-235.

Fuchs, Doris y Glaab, Katharina (2011). "Material Power or Normative Conflict: Determinants of the Interaction Between Global and Local Agrifood Governance". Ponencia presentada en la Convención Anual de ISA, Nuevo Orleans, 17-20 de Febrero.

Gasalla, Maria y de Castro, Fabio (2016). "Enhancing Stewardship in Latin America and Caribbean Small-Scale Fisheries: Challenges and Opportunities". Maritime Studies, 15(15), pp. 1-7. 
Glasbergen, Pieter (2013). "Legitimation of Certifying Partnerships in the Global Market Place”. Environmental Policy and Governance, 23, pp. 354-367.

Granovetter, Mark (1973). "The Strenght of Weak Ties". American Journal of Sociology, 6(78), pp. 1360-1380.

Guarin, Alejandro y Knorringa, Peter (2013). "New Middle-Class Consumers in Rising Powers: Responsible Consumption and Private Standards." $O x$ ford Development Studies, 42, pp. 151-171.

Hinrichs, Clare (2000). "Embeddedness and Local Food Systems: Notes on Two Types of Direct Agricultural Market". Journal of Rural Studies, 16, pp. 295-303.

Hinrichs, Clare (2016). "Fixing Food with Ideas of 'local' and 'place". Journal of Environmental Studies and Sciences, 6 (mayo), pp. 759-764.

Larson, Jorge (2004). "Programa Recursos Biológicos Colectivos". Biodiversitas, 53 (marzo), pp. 1-16.

Ley-Cooper, Kim (2010). "Developing Sustainability Principles and Criteria for Management and Eco-Labelling in the Sian Ka'an and Banco Chinchorro Biosphere Reserves, México". Congreso "Proceedings of the $63^{\text {rd }}$ Gulf and Caribbean Fisheries Institute", 1-5 de noviembre de 2010, pp. 52-59.

Ley-Cooper, Kim y Quintanar, Eduardo (2010). "Chakay: Marca colectiva con identidad de origen de las cooperativas de Quintana Roo". Biodiversitas, 90, pp. 10-15.

Ley-Cooper, Kim (2015). "Sustainability of Lobster Panulirus argus Fisheries in Marine Protected Areas in South-Eastern Mexico" (Tesis de doctorado en Ciencias Ambientales). Australia: Curtin University, 310 pp.

Lidskog, Rolf y Sundqvist, Goran (2018). "Environmental Expertise". En Magnus Bostrom y Debra Davidson (eds.), Environment and Society. Concepts and Challenges. Suiza: Palgrave Macmillan, pp. 167-186.

Lockie, Stewart; Travero, José, y Tennen, Rebeka (2015). "Private Food Standards, Regulatory Gaps and Plantation Agriculture: Social and Environmental (ir)Responsability in the Philippine Export Banana Industry”. Journal of Cleaner Production, 107, pp. 1-7.

Loconto, Allison (2015). "Assembling Governance: The Role of Standards in the Tanzanian Tea Industry". Journal of Cleaner Production, 107, pp. 64-73. 
McClenachan, Loren; Neal, Benjamin; Al-Abdulrazzak, Dalal; Witkin, Taylor; Fisher, Kara, y John Kittinger (2014). "Do community supported fisheries (CSFs) improve sustainability?". Fisheries Research, 157, pp. 62-69.

Miller, Alice y Bush, Simon (2014). "Authority without Credibility? Competition and Conflict between Ecolabels in Tuna Fisheries". Journal of Cleaner Production, 30, pp. 1-9.

Mol, Arthur (2018). "The Environmental State and Environmental Governance”. En Magnus Bostrom y Debra Davidson (eds.), Environment and Society. Concepts and Challenges. Suiza: Palgrave Macmillan, pp. 119142.

Moreno, Andrea; Bourillón, Luis; Flores, Eglé, y Fulton, Stuart (2016). "Fostering Fisheries Management Efficiency through Collaboration Networks: The Case of the Kanan Kay Alliance in the Mexican Caribbean”. Bulletin of Marine Science, 92, pp. 1-16.

Neilson, Jeff y Pritchard, Bill (2009). Value Chain Struggles. Institutions and Governance in the Plantation Districts of South India. Reino Unido: Blackwell Publishing, 320 pp.

Oosterveer, Peter (2018). "Global Environmental Networks and Flows Addressing Global Environmental Change”. En Magnus Bostrom y Debra Davidson (eds.), Environment and Society. Concepts and Challenges. Suiza: Palgrave Macmillan, pp. 95-118.

Pérez-Ramírez, Mónica (2011). "The Artisanal Lobster Fishery in Mexico”. The Lobsters Newsletter, 24(1), pp. 11-14.

Pérez-Ramírez, Mónica; Ponce-Díaz, Germán, y Lluch-Cota, Salvador (2012). "The Role of MSC Certification in the Empowerment of Fishing Cooperatives in Mexico: The Case of Red Rock Lobster Co-Managed Fishery". Ocean and Coastal Management, 63(2012), pp. 24-29.

Pérez-Ramírez, Mónica; Castrejón, Mauricio; Gutiérrez, Nicolás, y Defeo, Omar (2015). "The Marine Stewardship Council Certification in Latin America and the Caribbean: A Review of Experiences, Potentials and Pitfalls". Fisheries Research, 182 (octubre), pp. 50-58.

Ponte, Stefano y Cheyns, Emmanuelle (2013). "Voluntary standards, expert knowledge and the governance of sustainability networks." Global Networks, 13 (4), pp. 459-477. 
Ponte, Stefano; Gibbon, Peter, y Vandergeest, Jakob (2011). "Conclusion: The Current Status, Limits and Future of Governing through Standards". En Stefano Ponte, Peter Gibbon y Jakob Vandergeest (eds.), Governing through Standards: Origins, Drivers and Limitations. Reino Unido: Palgrave, pp. 289-303.

Ponte, Stefano (2012). "The Marine Stewardship Council (MSC) and the Making of a Market for Sustainable Fish”. Journal of Agrarian Change, 12(2-3), pp. 300-315.

Rasmussen, Julie; Friis-Hansen, Esbern, y Funder, Mikkel (2019). “Collaboration between Meso-Level Institutions and Communities to Facilitate Climate Change Adaptation in Ghana”. Climate and Development, 11(4), pp. 355-364.

Rosales, Rocío (2016). "Cadenas Sustentables de Valor y Certificaciones. ¿Nuevos mercados en búsqueda de nuevos consumidores?" 21 Encuentro Nacional sobre Desarrollo Regional en México. Mérida, Yucatán, 15-18 de noviembre de 2016.

Schouten, Greetje (2013). "Tabling Sustainable Commodities through Private Governance. Processes of Legitimization in the Roundtables on Sustainable Palm Oil and Responsible Soy" (Tesis de doctorado). Países Bajos: Universidad de Utrecht, 190 pp.

Schouten, Greetje y Bitzer, Verena (2015). “The Emergence of Southern Standards in Agricultural Value Chains: A New Trend in Sustainability Governance?". Ecological Economics, 120, pp. 175-184.

Schulz, Oliver (2017). "The Micro-Politics of Small-Scale Fisheries Governance in South Africa: A Case Study of Community-Based Political Representation as a Form of Brokerage". Maritime Studies, 16(7), pp. 1-21.

Suchman, Mark (1995). "Managing Legitimacy: Strategic and Institutional Approaches". The Academy of Management Review, 20(3), pp. 571-610.

Thi Anh, Pham; Bush, Simon; Mol, Arthur, y Carolien Kroeze (2011). "The Multi-Level Environmental Governance of Vietnamese Aquaculture: Global Certification, National Standards, Local Cooperatives". Journal of Environmental Policy and Planning, 13(4), pp. 373-397.

Vandergeest, Peter; Ponte, Stefano, y Bush, Simon (2015). "Assembling Sustainable Territories: Space, Subjects, Objects, and Expertise in Seafood Certification". Environment and Planning A: Economy and Space, 47(9), pp. 1907-1925. 


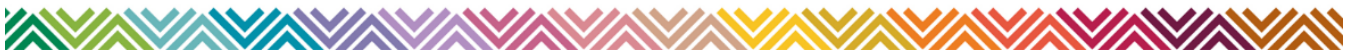

Van Koppen, Kris y Bush, Simon (2018). "Spatial Frames and the Quest for Institutional Fit". En Magnus Bostrom y Debra Davidson (eds.), Environment and Society. Concepts and Challenges. Suiza: Palgrave Macmillan, pp. 305-326.

Vellema, Sietze y Van Wijk, Jeroen (2015). "Partnerships Intervening in Global Food Chains: The Emergence of Co-Creation in Standard-Setting Certification”. Journal of Cleaner Production, 107 (noviembre), pp. 1-9.

Wentink, Carsten; Raemaekers, Serge, y Bush, Simon (2017). "Co-Governance and Upgrading in the South African Small-Scale Fisheries Value Chain”. Maritime Studies, 16(5), pp. 1-18.

\section{$\underline{\text { Sitios web consultados }}$}

Marine Stewardship Council: https://www.msc.org/

Editora asociada: Esperanza Tuñón Pablos Recibido: 27 de enero de 2020 Aceptado: 2 de julio de 2020 